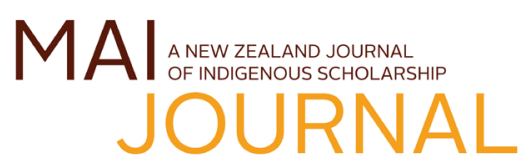

D0I: 10.20507/MAlJournal.2020.9.2.8

\title{
BODY SOVEREIGNTY AND TE MATATINI
}

\section{Thoughts from a kaimātakitaki}

\author{
Ashlea Gillon*
}

\begin{abstract}
This commentary explores the ways in which body sovereignty has been illustrated and supported in the sovereign space of Te Matatini (Ki Te Ao). It is suggested that the 2019 Te Matatini Ki Te Ao Kapa Haka Finals were a space that privileged Te Ao Māori and body sovereignty in multiple, intersecting ways. I propose that sovereign spaces such as Te Matatini provide an alternative illustration, discourse and narrative to current coloniality that restricts, limits and does not acknowledge body sovereignty. Te Matatini centres Māori bodies and Māori sovereignty through kapa haka and creates a space for multiple levels of body sovereignty, for multiple genders, different able-bodiedness and different sized bodies. Te Matatini Ki Te Ao centres tāngata Māori and creates a sovereign space for Māori bodies to exist and be valued.
\end{abstract}

\section{Keywords}

Māori, Te Matatini, body sovereignty, sovereign spaces, kapa haka, bodies

\section{Introductio}

Body sovereignty, both implicit and explicit, was seen at Te Matatini Ki Te Ao. As a kaimātakitaki experiencing my first Te Matatini, Aotearoa New Zealand's national kapa haka competition, from my Kaupapa Māori epistemology, I theorise it to be a sovereign space. This sovereign space occurred through immersion in and accessibility of te reo Māori, as well as being surrounded by thousands, tens of thousands of Māori whanaunga, living, breathing and just being Māori, however and whatever that means for us. Te Matatini Ki Te Ao created the space within which body sovereignty was re-normalised in various ways, including through the performances, the kaihaka, the language and dialects used, the peoples involved, the re-normalisation of tā moko and even the stalls that were operated by Kaupapa Māori businesses.
Thoughts from a kaimātakitaki are shared in this commentary concerning body sovereignty and sovereign spaces as ignited by Te Matatini Ki Te Ao.

\section{Body: Movements and sovereignty}

While it could be argued that Te Matatini was and is an illustration of body positivity, I suggest that it is a sovereign space in which Māori are re-centred, re-normalised and re-prioritised, and are able to enact and have body sovereignty recognised.

Body positivity is a movement primarily stemming from the struggle of fat people and fat activists to have their bodies acknowledged, accepted and treated equitably in society; additionally, it centres bodily (self) acceptance (Sastre, 2014). As a movement that has largely occurred on social media, although body positivity tries to centre inclusivity, often body positivity constructs: 
proprietary boundaries around normativity despite their paradoxical emphasis on dismantling bodily standards altogether. This move to create dedicated spaces wherein even the supposed diversity contained within an idea like bodily acceptance can be transformed into a prescribed set of visual and textual practices re-inscribes, rather than liberates, the body into a rubric of appropriate, self-conscious citizenship. (Sastre, 2014, p. 930)

Body positivity places emphasis on body size, and often perpetuates a white feminist view of self-love and self-acceptance. Though important, often the complexities of intersectionality are excluded from these discussions, and those who experience oppression in multiple forms are excluded and omitted from this "revolutionary" movement (Sastre, 2014). Additionally, the onus placed on a fat woman (of colour) to "love herself" and her body sees the invisibilisation of the inequitable systems and power structures that perpetuate systems of oppression. Body positivity often highlights the acceptance-driven societies we live and that "we should be striving for everyone to genuinely and authentically love themselves and the body they've been given" ("Body Positivity", 2014). Sastre (2014) suggests that "body positivity more closely mirrors than challenges a neoliberal paradigm of bodily compliance" (p. 929).

The lack of intersectionality regarding body positivity can limit the critical lens through which societal systems are explored as the causes of multiple oppressions (Crenshaw, 1991). Ethnicity (race in other contexts) is often omitted from body positivity conversations, as are able-bodiedness and age. Experiencing a restriction or disregard of body sovereignty as a white woman and experiencing it as a woman of colour can be vastly different. The racialisation of fatism and sexism means that women of colour are subject to multiple levels and instances of discrimination in various contexts (Crenshaw, 1991). This can perpetuate inaccessibility to societal resources, to stable housing or employment, and generally healthful living, which can contrast with white women's experiences. This is not to compare the two, but to highlight the various ways in which body sovereignty can be disregarded or restricted through multiple systems of oppression. It illustrates the hierarchy of systems of oppression that permeate our lives and restrict access to goods, services and opportunities based on ethnicity or race (Jones, 2000), sex or gender (Cudd \& Jones, 2007) and fatness (Pausé, 2014, 2017).

What body positivity has done is create a space for dialogue to occur in a more widely accessible way to others, not just those who experience these oppressions. It is important to note that loving your body and yourself is not a bad thing; it often can provide a political re-visualisation of bodies that can be classified as deviant and are often less re-presented, through body positive imagery (Pausé, 2014). This step in the re-normalisation process is important and re-iterates the quest for re-presentation that non-white people seek within society. However, body positivity's critique of systemic oppression can be limited. This is a space for body sovereignty.

Body sovereignty is centred around:

the general need to feel safe from physical harm and in control of and able to make decisions about the body ... in terms of health, body sovereignty is located in particular discourses about women's ability to have jurisdiction over their bodies (e.g., sexual assault, sterilization, reproductive rights, childbirth) . . . The concept of body sovereignty fits in the context of other conversations around health and autonomy. (Ivancic, 2017, p. 4)

Cole (2017) suggests that body sovereignty is the “opposite of body submission" (p. 2) and body submission stems from patriarchy as an oppressive paradigm that re-frames and re-presents women's bodies in negative ways, such as before pictures, objectifications and commodities "available for the input of and control from others" (p. 2). She goes on to suggest that body sovereignty is both the inhabitancy of bodies, and protection and respect of your choices and boundaries. However, Cole also suggests that body submission is "giving up of our physical sovereignty" (p. 2); nevertheless, this fails to acknowledge that body sovereignty is disregarded or not acknowledged by others also, much like Indigenous sovereignties. It fails to provide an intersectional lens to explore how body sovereignty can be restricted or disregarded for some and not for others. Additionally, she acknowledges that having body sovereignty is a privilege that requires utilising our positions to advocate for those who do not, meaning all bodies (Cole, 2017). I would argue that having your body sovereignty recognised is actually the privilege.

When considering body sovereignty, Troost (2008) alludes to ownership and asks "how much of our bodies do we truly own, subconsciously, legally, and socially?" (p. 172). Similarly to Cole (2017), Troost (2008) goes on to suggest that placing an emphasis on body sovereignty acknowledges and supports intersectional approaches to resisting oppressive systems. She infers that: 
if we organize around body sovereignty, we won't have only the strength of feminists behind us ... nor only the strength of the sex-positive, polyamorous, and BDSM communities ... nor only fat people ... we'll have the sum of everyone who wants their body back. (Troost, 2008, p. 172)

While agreeing with Troost's theorising, I maintain that the use of the concept of ownership and having one's body returned perpetuates this notion of commodifying bodies and that some bodies are worthier of ownership. Additionally, it implies that we do not "own" our bodies, a concept that does not have the same meaning to Mãori. In this sense, Māori can be seen as mana tinana (Gillon, 2019), people who hold authority or guardianship over our bodies. It is not that we do not "own" our bodies; it is that our "ownership" or more specifically our authority, autonomy and sovereignty over ourselves and our bodies, as well as that more broadly, is not being recognised by those in positions of power, by policy, by systems that structure and assign access (Jackson, 1994; Reid, 2011). This denial of recognition, like racism, sexism and fatism, is systemic and personally mediated by individuals, as well as internalised, as can be illustrated by body positivity movements.

I theorise that body sovereignty is both the individual level acceptance and enactment of autonomy of our bodies, and the collective recognition and accessibility of that sovereignty and autonomy peoples have. At an individual level, it centres access to the ability to make decisions concerning the body and to have access to resources to do so (Ivancic, 2017); it also centres utilising a critical gaze upon ourselves and how we can perpetuate systems of oppression by personally mediating them (Kumagai \& Lypson, 2009), and applying this critical gaze upon systems of oppression themselves and how they restrict or disregard body sovereignty. At a collective level, it is also about identifying ways in which these systems restrict certain collectives from being able to achieve an individual-level body sovereignty. The recognition of the ways in which systems of oppression limit, disregard and restrict body sovereignty is central to deconstructing them.

It is important to note that body sovereignty as a process does not explicitly have to be labelled as such. As illustrated at Te Matatini Ki Te Ao, body sovereignty was displayed in multiple ways. This seems to centre around sovereign spaces.

\section{He aha tērā kaupapa}

Kapa meaning group or in lines, haka meaning performance or dance, kapa haka are performances to tell a story (Mazer, 2011; Whitinui, 2010). Whitinui (2010) proposes that kapa haka can be understood as a cultural taonga "passed down through the ages from one generation to the next where individuals are able to share their life stories through creative self-expression and pure emotion" (p. 4).

Kapa haka involves utilising alternative learning environments and teaching pedagogy from Eurocentric colonial systems to convey intricate cultural expression that creates and brings to light both historical and contemporary stories through te reo Māori and the body ("Kapa Haka”, 2011; Whitinui, 2010). In this respect, kapa haka provides both an individual and collective expression, and acknowledgement of body sovereignty. Kapa haka is intrinsically linked to identity, wellness, educational achievement, transformation, creativity and re-vitalisation of te reo me ōna tikanga, and provides a strengths-based Māori space (Pihama et al., 2014; Whitinui, 2010).

\section{Te Matatini}

Te Matatini is the biennial national kapa haka festival. Te Matatini was previously known as the first Māori performing arts festival, and was established in the 1970 s as a means to promote the re-vitalisation of te reo Māori due to colonial theft and denial of the language (Pihama et al., 2014), a way to illustrate the various forms and progression of tikanga Māori and also as a means to honour hapū, iwi and collective stories from our peoples in waiata and haka (Mazer, 2011). According to Te Matatini (2019), the purpose of Te Matatini is to "foster, develop and protect kapa haka in the pursuit of excellence".

It can provide a platform for resistance to Pākehā coloniality while celebrating all things Māori. Although Te Matatini centres kapa haka performance, it also creates discussion. It provides re-presentation about relevant issues at hapū, iwi and collective levels to other hapū, iwi and collectives and to the Aotearoa government (Pihama et al., 2014; Whitinui, 2010).

The performances of kaihaka are pūrākau that are created by weaving of spoken and visual storying that can challenge inequity (Lee, 2009). Kapa haka as a part of Te Matatini involves a variety of performance types, such as waiata tira, which involves bringing the kapa to a state of rangimārie to settle the nerves; whakaeke, which is the entrance and basically introduces the kapa, their 
whakapapa and where they are from, and the kaupapa of their performance; mōteatea; and waiata $\bar{a}$ ringa-Ngata and Armstrong (2002) suggest that it "is not a series of drill movements but a rhythmic expression of moods and emotions" (p. 9); poi, typically a ball on plaited cord; haka, which is often used to illustrate political statements; and the whakawātea, which is the exit and final statement by the kapa that acknowledges what they have said and done and the mana whenua of that area (Te Matatini Kapa Haka Aotearoa, 2019).

Te Matatini Ki Te Ao ki Te Whanganui-a-Tara, attended by over 50,000 people ("Te Matatini in Wellington", 2019), has provided illustrations of multiple ways that Māori acknowledge and enact body sovereignty at both individual and collective levels. The means by which body sovereignty is outwardly expressed and supported include traditional kākahu that embraces, re-normalises and exposes parts of bodies that westernised cultural norms restrict or hide, especially within Indigenous cultures (Howard, 2011); the limited age restrictions around kaihaka partaking in kapa haka at Te Matatini; the unrestricted fatness and size of kaihaka, re-normalisations of various body shapes and sizes; moko kauae and mataora accepted and re-normalised; the able-bodiedness of kaihaka and the inclusiveness of those who are differently abled; and whose language is re-prioritised and the accessibility of te reo through live translation applications.

A strong example of body sovereignty was the illustration and exposure of various body sizes as a re-normalising process. The kākahu worn by multiple kaihaka from several kapa provided re-visualisations of bodies of diverse size. The unquestioned inclusion of kaihaka of varied body sizes reinforced ideas of inclusion and body sovereignty throughout Te Matatini Ki Te Ao. This re-normalisation also provided a counter-narrative to colonial, essentialist ideas that perpetuate narrow imagery of Indigenous bodies (Howard, 2011; Smith, 2012). The (re)-exposure of bodies and fatness of kaihaka at Te Matatini also reinforced the idea that Māori are defined by Māori and not colonial characterisations (Gillon, 2016). The general acceptance and re-presentation of fat bodies within Te Matatini emphasised the recognition of individual-level body sovereignty through inclusion and re-visualisation processes.

Additionally, multiple moko kauae and mataora provided further re-visualising of Māori peoples, Māori bodies and body sovereignty through the reclamation of this ancestral taonga, as well as the re-production of these on kaihaka.
The unquestioned acknowledgement and recognition of tā moko at Te Matatini illustrated some of the multiple ways in which body sovereignty was enacted.

\section{Sovereign spaces and layers, he aha èrā}

Though the ability to have sovereign spaces or sovereignty is contested and complex, it is important to note their role. Part of the complexity regarding sovereign spaces lies with the colonial realities in which we reside. A pātai my friends and I have been pondering recently is, Can you have a sovereign space within colonised societies? I propose that this depends on how you understand sovereignty and its fluidity.

Previously to unsettlers' arrival, sovereignty was enacted and recognised much differently to how sovereignty is currently understood and (not) recognised; additionally, Māori never ceded sovereignty (Jackson, 1993, 1994). Achieving the same type of sovereignty and recognition of te tino rangatiratanga that iwi and hapū had before unsettlers' arrival would be extremely complex within the current colonial state in which Māori and many Indigenous peoples reside, and beyond the scope of this commentary. However, this idea that Māori were static fails to recognise the progressive, fluid nature of our peoples, and our conceptualisations and enactments of processes, such as tino rangatiratanga. This implies that sovereignty is a fixed transactional state. However, as with all Indigenous peoples, adaptability, progression and exploration have been central to our being and our development (Jackson, 1993). To disregard that in relation to our sovereignty is naive and fails to recognise that tikanga is fluid and tino rangatiratanga is malleable to new contexts. Although sovereignty can be understood as a process and outcome, and should be at a collective iwi Māori level, I propose that sovereign spaces are still possible within colonial societies.

Sovereign spaces are those in which Indigenous peoples are centralised, have control over and can exhibit themselves however they wish. Some examples of sovereign spaces are Te Matatini, the Merrie Monarch Festival in Hawai'i and the Indigenous peoples' Pow Wow on Turtle Island. What is important to note about the examples provided is that these can also be seen as a performance of culture and essentialising Indigeneity (Smith, 2012). While I do acknowledge that colonial understandings and interpretations of Indigenous cultural performance can perpetuate inaccurate, colonial, racist stereotypes of Indigeneity (Smith, 2012), I argue that these spaces 
centre Indigenous languages (such as Te Matatini providing live translations, thus increasing the accessibility of te reo), and performance as a way of illustrating Indigenous relationships, discussing (Indigenous) politics and centring Indigenous peoples, on Indigenous terms. Other examples I theorise of sovereign spaces within coloniality are Māori-medium schooling; pōwhiri and marae; IRONMĀORI, the world's biggest Indigenous triathlon that takes place within a Kaupapa Māori environment (Durie et al., 2012); and spaces for ceremony such as kava circles (Tecun, 2017), or sweat lodges.

In sovereign spaces, enactment of body sovereignty in multiple forms is re-normalised. From the re-visualisations of bodies, accessing Te Ao Māori, to re-centring Māori bodies and re-normalising bodies of different sizes, fatness and abledness, Te Matatini provides space for body sovereignty. Part of the ways body sovereignty was expressed at $\mathrm{Te}$ Matatini was through multi-level autonomy. This was illustrated through kapa or rōpū exhibiting and expressing rohe-based sovereignty, as well as collective and individual body sovereignty. As a multi-level sovereign space, Te Matatini allows for displays of body sovereignty in multiple, complex ways.

Te Matatini not only allows for the expression of sovereignty and body sovereignty, but it creates a space for people to also acknowledge levels of sovereignties. This included not entering the arena while kapa were performing, not taking photographs or videos without consent, Māori businesses selling Māori-made goods, people watching performances in ways that allowed the kapa to be (re-) centred, and the accessibility of te reo Māori and translations into English. Te Matatini as a space created by Māori reinforced ideas of inclusiveness while maintaining a critical, decolonial positioning on systems of oppression that inhibit and fail to recognise (body) sovereignty. The inclusivity of $\mathrm{Te}$ Matatini was exemplified through who performs, who is involved, who the judges are, who the kaihaka are, and what messages are being shared and how within that sovereign space.

Kapa haka is a form of body sovereignty in the messages it sends, how it is accessible and the kaihaka who are involved who experience various and multiple identities at a time. Te Matatini Ki Te Ao provided a space, both physical and spiritual for body sovereignty to be enacted, for decision-making processes concerning bodies to be re-normalised, acknowledged and accepted, and a version of sovereignty. Body sovereignty is complex and involves an intersection of identities, power and agency. Often the ways in which people and bodies are re-presented, read and gazed upon are dictated by societal and colonial discourses, and "norms" (Ritenburg et al., 2014). However, from a kaimātakitaki perspective, Te Matatini Ki Te Ao provides a space that creates an alternative to that narrative.

\section{Glossary}

Aotearoa

haka

hapū

he aha èrā

iwi

kaihaka

kaimātakitaki

kākahu

kapa

kapa haka

Kaupapa Māori

mana tinana

mana whenua

Māori

marae

mataora

moko

moko kauae

mōteatea

Pākehā

pātai

pōwhiri

pūrākau

poi

rangimārie

rohe
Land of the long white cloud, New Zealand

cultural, posture performance

sub-tribal grouping, extended whānau network

what are those

tribal grouping, extended whānau network

haka performer

spectator, observer

clothing

group

group that performs haka

Māori approach, Māori principles, Māori agenda, an ideology, Māori theories, methodologies and epistemologies

people who hold mana, guardianship or jurisdiction over their bodies

people who hold mana, guardianship or jurisdiction of an area

Indigenous peoples of Aotearoa tribal meeting grounds male facial moko, Māori tattoo cravings into the skin, Māori tattoo

female chin moko, Māori tattoo

laments

a person of predominantly European descent

question

welcome ceremony

ancient legend, myth

a light ball on a string of varying length that is swung or twirled rhythmically; traditionally a weapon/tool used to strengthen wrists peace, peacefulness, harmony region, area 


\begin{tabular}{|c|c|}
\hline rōpū & group \\
\hline tā moko & to apply moko, Māori tattoo \\
\hline tāngata & people \\
\hline aonga & cultural treasure \\
\hline e Ao Māori & $\begin{array}{l}\text { Māori World, Māori } \\
\text { worldview }\end{array}$ \\
\hline Te Matatini & $\begin{array}{l}\text { The National kapa haka } \\
\text { competition; mata-face, } \\
\text { tini-many }\end{array}$ \\
\hline $\begin{array}{l}\text { te reo me ōna } \\
\text { tikanga }\end{array}$ & $\begin{array}{l}\text { language and cultural practices } \\
\text { and protocols }\end{array}$ \\
\hline $\begin{array}{l}\text { Te Whanganui- } \\
\text { a-Tara }\end{array}$ & Wellington \\
\hline tino rangatiratanga & $\begin{array}{l}\text { sovereignty, self-determination, } \\
\text { autonomy }\end{array}$ \\
\hline waiata & song \\
\hline waiata ā ringa & action songs using the body \\
\hline waiata tira & choral song \\
\hline whakaeke & $\begin{array}{l}\text { entrance (e.g. onto a stage), } \\
\text { entrance song, entrance } \\
\text { item-a term used for } \\
\text { the item of a traditional } \\
\text { performing arts competition } \\
\text { during which the performing } \\
\text { group takes the stage }\end{array}$ \\
\hline whakawātea & $\begin{array}{l}\text { exit, exit song, exit item-a } \\
\text { term used for the final item } \\
\text { of a traditional performing } \\
\text { arts competition during } \\
\text { which the performing group } \\
\text { retreats from the stage }\end{array}$ \\
\hline whānau & $\begin{array}{l}\text { more than family, extended } \\
\text { familiar group, relations, } \\
\text { connections }\end{array}$ \\
\hline whanaunga & $\begin{array}{l}\text { relative, relation, kin, blood } \\
\text { relation }\end{array}$ \\
\hline
\end{tabular}

\section{References}

Body positivity. (2014, February 24). UWIRE Text. http://link.galegroup.com/apps/doc/A359623381/ AONE? $\mathrm{u}=$ learn\&side $=$ AONE $\&$ xid $=\mathrm{e} 9 \mathrm{a} 7 \mathrm{e} 696$

Cole, R. (2017). Body Sovereignty. Simon Fraser Public Interest Research Group. https://sfpirg.ca/ wp-content/uploads/2017/08/BODY-SOVEREIGNTYRACHEL.pdf

Crenshaw, K. (1991). Mapping the margins: Intersectionality, identity politics, and violence against women of color. Stanford Law Review, 43(6), 1241-1299. http://doi.org/dn82xw

Cudd, A. E., \& Jones, L. E. (2007). Sexism. In R. G. Frey \& C. H. Wellman (Eds.), A companion to applied ethics (pp. 102-118). Blackwell Publishing.

Durie, M., Hoskins, T. K., \& Jones, A. (2012). Interview: Kaupapa Māori: Shifting the social. New Zealand Journal of Educational Studies, 47(2), 21-29.

Gillon, A. (2016). "Oh you don't look Māori”: Social ascription and te haerenga o tuakiri: The journey of identity [Master's thesis, University of Auckland]. ResearchSpace. https://researchspace.auckland. ac.nz/handle/2292/32400

Gillon, A. (2019). Fat Indigenous bodies and body sovereignty: An exploration of re-presentations. Journal of Sociology. Advance online publication. https://10.1177/1440783319893506

Howard, M. C. (2011). Transnationalism and society: An introduction. McFarland \& Company.

Ivancic, S. R. (2017). Body sovereignty and body liability in the wake of an "obesity epidemic": A poststructural analysis of the soda ban. Health Communication, 33(10), 1243-1256. http://doi. org/dtjr

Jackson, M. (1993). Land loss and the Treaty of Waitangi. In W. Ihimaera (Ed.), Te ao marama: Regaining Aotearoa-Māori writers speak out (Vol. 2, pp. 70-78). Reed Books.

Jackson, M. (1994). Changing realities: Unchanging trusts. Australian Journal of Law and Society, 10, 115-131.

Jones, C. (2000). Levels of racism: A theoretic framework and a gardener's tale. American Journal of Public Health, 90(8), 121-125. http://doi.org/ b56wkw

Kapa Haka: Te Matatini-the evolution of kapa haka. (2011). DANZ Quarterly, 24, 6-7. https://cdnflightdec.userfirst.co.nz/uploads/sites/danz/files/ DANZ\%20Magazine/The_Evolution_of_Kapa_ Haka.pdf

Kumagai, A. K., \& Lypson, M. (2009). Beyond cultural competence: Critical consciousness, social justice, and multicultural education. Academic Medicine, 84(6), 782-787. http://doi.org/bjk4qm

Lee, J. (2009). Decolonising Māori narratives: Pūrākau as a method. MAI Review, 2, Article 3. http://www. review.mai.ac.nz/mrindex/MR/article/download/ 242/242-1618-1-PB.pdf

Mazer, S. (2011). You talkin' to me? Eavesdropping on the conversation at Te Matatini Māori Performing Arts Festival. Performance Research, 16(2), 44-49. http://doi.org/cq8rhb

Ngata, R., \& Armstrong, A. (2002). Māori action songs: Words and music, action and instructions. Reed Books.

Pausé, C. (2014). Die another day: The obstacles facing fat people in accessing quality healthcare. Narrative Inquiry in Bioethics, 4(2), 135-141. http://doi. org/dtjs

Pausé, C. (2017). Borderline: The ethics of fat stigma in public health. The Journal of Law, Medicine \& Ethics, 45(4), 510-517. http://doi.org/gcvv44

Pihama, L., Tipene, J., \& Skipper, H. (2014). Ngā hua a tāne rore: The benefits of kapa haka: Scoping the research needs and options for developing a better understanding of the contribution that Kapa Haka makes to Aotearoa New Zealand society (Scoping Report for Te Manatū Taonga and Te Matatini). Manatū Taonga-Ministry for Culture and Heritage.

Reid, P. (2011). Good governance: The case of health equity. In V. Tāwhai. \& K. Sharpe (Eds.), Always 
speaking: The Treaty of Waitangi and public policy (pp. 35-48). Huia Publishers.

Ritenburg, H., Leon, A. E. Y., Linds, W., Nadeau, D. M., Goulet, L. M., Kovach, M., \& Marshall, M. (2014). Embodying decolonization: Methodologies and indigenization. AlterNative: An International Journal of Indigenous Peoples, 10(1), 67-80. http:// doi.org/dtjt

Sastre, A. (2014). Towards a radical body positivity. Feminist Media Studies, 14(6), 929-943. http:// doi.org/dtjv

Smith, L. T. (2012). Decolonizing methodologies: Research and indigenous peoples (2nd ed.). Zed Books.

Tecun, A. (2017). Tongan kava: Performance, adaption, and identity in diaspora. Performance of the Real E-Journal, 1(1), 52-64.

Te Matatini in Wellington: It's been exhilarating, says organiser. (2019, February 25). RNZ. https:// www.rnz.co.nz/news/te-manu-korihi/383280/ te-matatini-in-wellington-it-s-been-exhilaratingsays-organiser

Te Matatini Kapa Haka Aotearoa. (2019). Ngā ture o te whakataetae: Competition rules. https://www.tema tatini.co.nz/fileadmin/Publications_and_Resources/ Nga-Ture-o-Te-Whakataetae-Competition-RulesTe-Matatini-National-Kapa-Haka-Festival-2019. pdf

Troost, H. C. (2008). Reclaiming touch: Rape culture, explicit verbal consent, and body sovereignty. In J. Friedman \& J. Valenti (Eds.). Yes means yes!: Visions of female sexual power and a world without rape (pp. 171-176). Seal Press.

Whitinui, P. (2010). Indigenous-based inclusive pedagogy: The art of kapa haka to improve educational outcomes for Māori students in mainstream secondary schools in Aotearoa, New Zealand. International Journal of Pedagogies and Learning, 6(1), 3-22. http://doi.org/d66747 